\title{
OBTENCIÓN DE PASTA Y SALSA DE ROCOTO (Capsicum sp.)
}

\author{
Responsable : Ing. Luis Alberto Marin Aliaga \\ Miembros Ing. Rolando Céspedes Rossel \\ Mgr. Nicolás Sequeiros Flores
}

\section{RESUMEN}

Se determinaron las medidas biométricas y la composición quimica del rocoto. El tratamiento efectuado fue: Materia prima, selección y despedunculado, lavado, desinfección, cortado, molienda, estandarizado, mezclado, pasteurizado, envasado, enfriado, y almacenado.

Se realizaron pruebas de añadido de sal de 1, 2, 3, 4 y 5\%, siendo su proporción óptima de $3 \%$. Se preparó la salsa de rocoto con añadido de pulpa de tomate de árbol en cantidades de 30 , 40,50 y $60 \%$; la más adecuada fue de $50 \%$. Se ajustó el $\mathrm{pHa} 3,8$ 4,0 . La cantidad de agua adicionada fue de $1,51 / 20 \mathrm{~kg}$, benzoato de sodio $0,02 \%$ yácido citrico $0,2 \%$.

\section{INTRODUCCIÓN}

La alimentación en el Perú es conocida por su versatilidad y variados ingredientes, entre ellos el rocoto, por lo que es importante desarrollar tecnologias que permitan hacer más sencillo su uso y además aumentar el periodo de vida de la materia prima.

El auge que en los últimos años tiene la incorporación de nuevos productos que sirven como acompañamiento a las diferentes comidas va en aumento, por lo que se desarrolló el presente trabajo.

Una forma de aprovechamiento es la elaboración de salsa de rocoto, el que debe ser esterilizado por el pH de 4,80 que presenta, por lo que se debe disminuir esta caracteristica, para someterlo a una pasteurización. Se elaboraron pasta y salsa de rocoto obteniéndose esta última con un añadido de pulpa de tomate de árbol.

Se fijaron los objetivos siguientes:

- Evaluar las caracteristicas fisicoquímicas del rocoto.

- Determinar los parámetros tecnológicos de procesamiento de pasta y salsa de rocoto con añadido de pulpa de tomate de árbol.

\section{MATERIAL YMÉTODOS}

\section{1) Lugar de Ejecución}

El presente trabajo se llevó a cabo en los laboratorios de Análisis de los Alimentos, Tecnologia de los Alimentos, Evaluación Sensorial y Microbiología de los Alimentos de la Facultad de Ingenieria en Industrias Alimentarias de la Universidad Nacional Jorge Basadre Grohmann.

\section{2) Materia Prima, Insumos y Equipos:}

\section{Materia Prima:}

Se empleó rocoto (Capsicum sp.) producido en la región Tacna y tomate de árbol (Cyphomandra betacea send) obtenida de Sandia - Puno, ambos con un grado de madurez apropiado para llevar a cabo las diferentes pruebas.

\section{Insumos:}

Cloruro de sodio, ácido cítrico, benzoato de potasio, agua destilada.

\section{Equipos:}

Estufa Memmert, mufla, pHmetro, balanzas, licuadora industrial, cocina de gas, equipo Soxhlet, equipo de destilación semimicro kjeldal, mesas, agitadores, mecheros, envase de vidrio de $250 \mathrm{cc}$, etc.

\section{3) Métodos Analíticos de Control}

\section{De la Materia Prima:}

- Se realizaron determinaciones de las medidas biométricas y componentes del rocoto.

- Determinación de humedad, acidez total, pH, vitamina C.

\section{DelProducto Final}

- Se efectuaron análisis microbiológicos con recuento de bacterias aeróbicas mesófilos, coliformes totales, hongos ylevaduras. 
4) Pruebas Experimentales

En la Figura $N^{\circ} 01$ se muestra un flujograma para la elaboración de pasta y salsa de rocoto.

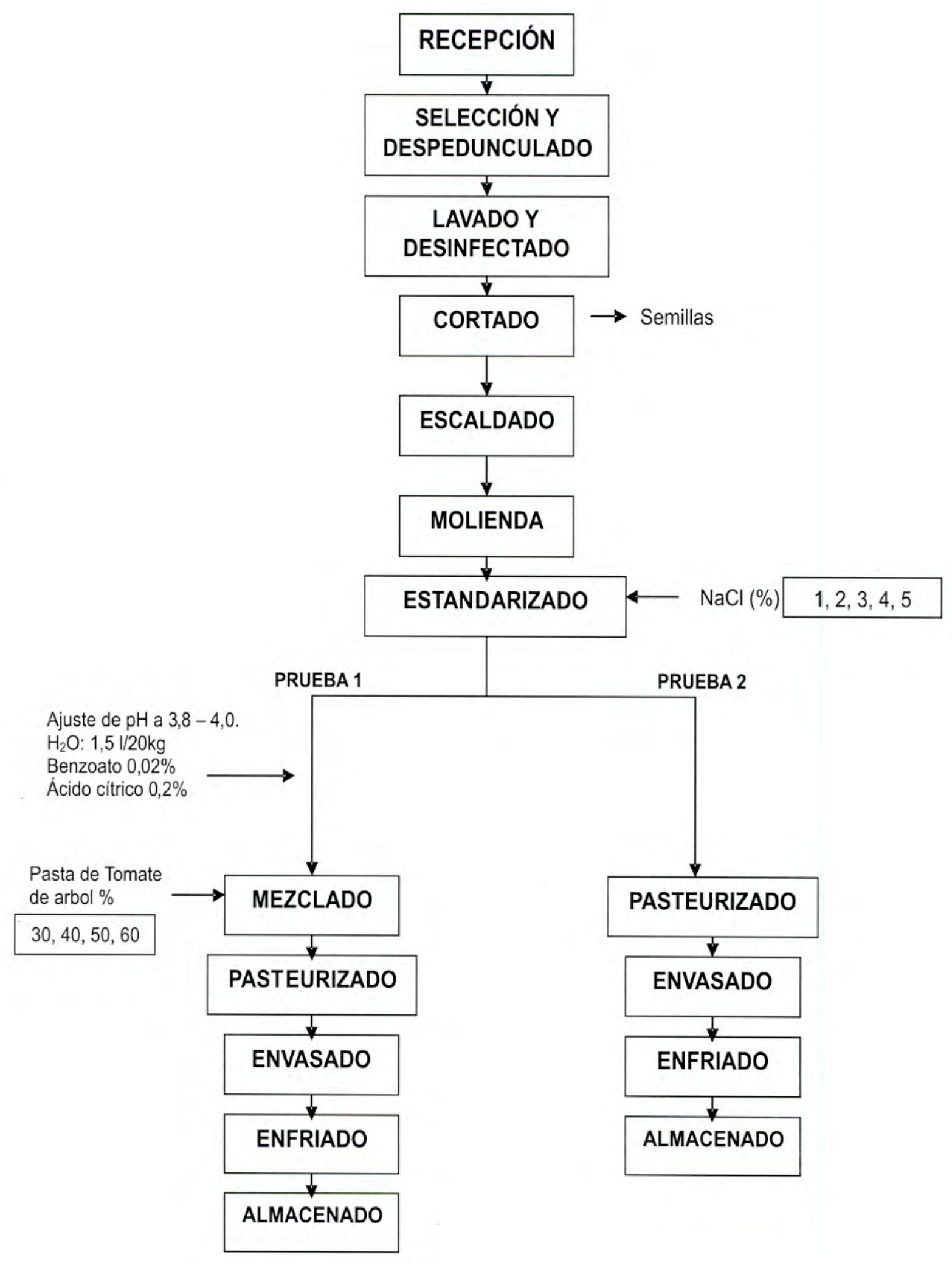

Figura $\mathrm{N}^{\circ}$ 01: Flujograma para elaboración de pasta y salsa de rocoto 


\section{RESULTADOS Y DISCUSIÓN}

En los cuadros 01,02 y 03 , se muestran las medidas biométricas, componentes y determinaciones quimicas del rocoto. Cabe resaltar que el contenido de vitamina $\mathrm{C}(29,61$ $\mathrm{mg}$ ) es importante y tiene relación con lo reportado por Collazos, 1975.

Cuadro $\mathrm{N}^{0} 01$.- Medidas biométricas del rocoto

\begin{tabular}{|c|c|c|c|c|c|c|c|c|}
\hline \multicolumn{3}{|c|}{ PEQUEÑOS } & \multicolumn{3}{c|}{ MEDIANOS } & \multicolumn{3}{c|}{ GRANDES } \\
\hline $\begin{array}{c}\text { Peso } \\
\mathbf{g}\end{array}$ & $\begin{array}{c}\text { Largo } \\
\mathbf{c m}\end{array}$ & $\begin{array}{c}\text { Ancho } \\
\mathbf{c m}\end{array}$ & $\begin{array}{c}\text { Peso } \\
\mathbf{g}\end{array}$ & $\begin{array}{c}\text { Largo } \\
\mathbf{c m}\end{array}$ & $\begin{array}{c}\text { Ancho } \\
\mathbf{c m}\end{array}$ & $\begin{array}{c}\text { Peso } \\
\mathbf{g}\end{array}$ & $\begin{array}{c}\text { Largo } \\
\mathbf{c m}\end{array}$ & $\begin{array}{c}\text { Ancho } \\
\mathbf{c m}\end{array}$ \\
\hline 61,24 & 5,96 & 5,04 & 78,58 & 5,22 & 5,72 & 108,36 & 6,01 & 6,83 \\
\hline 62,65 & 5,75 & 4,81 & 65,65 & 7,09 & 5,20 & 92,42 & 4,91 & 6,50 \\
\hline 60,55 & 5,09 & 5,08 & 74,64 & 5,38 & 5,83 & 95,61 & 5,74 & 6,19 \\
\hline 61,72 & 5,81 & 4,92 & 76,41 & 6,32 & 5,61 & 94,61 & 5,94 & 6,72 \\
\hline
\end{tabular}

En el Cuadro 02 se puede apreciar los componentes del rocoto, según su contenido de semillas, pedúnculos y pulpa. Cabe resaltar que el contenido de pulpa es alto: $84,74 \%$.

Cuadro ${ }^{\circ}$ 02.- Componentes de la pulpa de Rocoto

\begin{tabular}{|c|c|c|}
\hline COMPONENTES & PESO $(\mathbf{g})$ & PORCENTAJE \\
\hline Pedúnculos & 27,60 & 4,67 \\
\hline Semilla & 62,40 & 10,57 \\
\hline Pulpa & 500,16 & 84,76 \\
\hline Total & $\mathbf{5 9 0 , 1 0}$ & $\mathbf{1 0 0 , 0 0}$ \\
\hline
\end{tabular}

En el Cuadro 03 , se muestran las determinaciones químicas realizadas en la pulpa de rocoto.

Cuadro $N^{\circ}$ 03.- Determinación quimicas de la Pulpa de rocoto por $100 \mathrm{~g}$ de porción comestible.

\begin{tabular}{|l|c|}
\hline DETERMINACION & CONTENIDO \\
\hline Vitamina C $(\mathrm{mg})$ & 29,61 \\
\hline Acidez Total & 2,12 \\
\hline pH & 4,75 \\
\hline
\end{tabular}

En los Cuadros 04 y 05 se muestran los análisis de varianza y prueba de Duncan en la elaboración de salsa de rocoto, referido a la cantidad de sal.

Cuadro $\mathbf{N}^{\circ}$ 04.- Análisis de varianza en la elaboración de salsa de rocoto, referido a la cantidad de sal.

\begin{tabular}{|l|c|c|c|c|}
\hline \multicolumn{1}{|c|}{ F.V. } & G.L. & S.C. & C.M. & F.C. \\
\hline Entre tratamientos & 4 & 14,12 & 3,53 & 8,316 \\
\hline Error & 45 & 19,1 & 0,4244 & \\
\hline Total & 49 & 33,22 & & \\
\hline
\end{tabular}

\section{$F_{c}=8,316 \quad F c>F t$}

$\mathrm{Ft}=2,575 \quad 8,316>2,575$

Estos resultados indican que hay preferencia estadisticamente significativa entre los tratamientos.
Cuadro $N^{\circ} 05 .-$ Prueba de Duncan referente a la cantidad de sal añadida a la salsa de rocoto.

\begin{tabular}{|c|c|c|c|c|}
\hline $\mathrm{N}^{\circ}$ de Orden & Tratamiento & Promedio & Duncan & \\
\hline 1 & C & 4,3 & a & \\
\hline 2 & A & 3,4 & b & \\
\hline 3 & B & 3,3 & b & c \\
\hline 4 & D & 2,9 & b & c \\
\hline 5 & E & 2,8 & b & c \\
\hline
\end{tabular}

Los resultados indican que hay significancia a favor del tratamiento $\mathrm{C}$, es decir, $3 \%$ de añadido de sal.

En los cuadros 06 y 07 se muestran los análisis de varianza y prueba de Duncan, referido a la proporción de tomate de árbol: pulpa de rocoto, los que precisan que hay significación a favor del tratamiento $\mathrm{C}$, es decir, 50:50 de cada pulpa.

Cuadro $\mathbf{N}^{\circ}$ 06.- Análisis de varianza referido a la proporción de tomate de árbol: pasta de rocoto.

\begin{tabular}{|l|c|c|c|c|}
\hline \multicolumn{1}{|c|}{ F.V. } & G.L. & S.C. & C.M. & F.C. \\
\hline Entre tratamientos & 3 & 13,8 & 4,6 & 4,987 \\
\hline Error & 36 & 33,2 & 0,922 & \\
\hline Total & 39 & 47 & & \\
\hline
\end{tabular}

$\mathrm{FC}_{\mathrm{C}}=4,987, \mathrm{Ft}=2,86, \mathrm{FC}>\mathrm{Ft}$

Cuadro N07.-Prueba de Duncan referido a la proporción de pasta de tomate de árbol: pasta de rocoto

\begin{tabular}{|c|c|c|cc|}
\hline$N^{\circ}$ de Orden & Tratamientos & Promedio & Duncan al $\mathbf{5 \%}$ \\
\hline 1 & C & 3,5 & a & \\
\hline 2 & A & 2,3 & & b \\
\hline 3 & B & 2,2 & b & c \\
\hline 4 & D & 2,0 & b & c \\
\hline
\end{tabular}

Los resultados que se aprecian, indican que hay significación a favor del tratamiento $\mathrm{C}$, es decir, 50:50 de cada pulpa.

En el Cuadro 08 se muestra que la salsa y la pasta de rocoto fueron sometidas a pruebas microbiológicas, siendo ambos adecuados para el consumo humano.

Cuadro $N^{0}$ 08.- Resultados de análisis microbiológicos de la pasta y salsa combinada de rocoto.

\begin{tabular}{|l|c|c|}
\hline \multirow{2}{*}{ Determinación } & \multicolumn{2}{|c|}{ Número de colonias } \\
\cline { 2 - 3 } & $\begin{array}{c}\text { Pasta de } \\
\text { rocoto }\end{array}$ & $\begin{array}{c}\text { Salsa combinada } \\
\text { de rocoto }\end{array}$ \\
\hline Coliformes total & Ausencia & Ausencia \\
\hline Hongos y levaduras & $<10 \mathrm{ufc/g}$ & $<10 \mathrm{ufc} / \mathrm{g}$ \\
\hline $\begin{array}{l}\text { Bacterias aerobias y } \\
\text { mesófilos viables }\end{array}$ & $50 \mathrm{ufc} / \mathrm{g}$ & $40 \mathrm{ufc} / \mathrm{g}$ \\
\hline
\end{tabular}

Ufc: Unidad formadora de colonias. 


\section{CONCLUSIONES}

1. El rocoto es una hortaliza de la cual puede elaborarse una pasta que combinada con la pulpa de tomate de árbol se obtiene la salsa de rocoto de adecuadas características organolépticas.

2. El flujo óptimo para el procesamiento de salsa de rocoto fue: Materia prima, selección y despedunculado, lavado y desinfectado, cortado, escaldado, molienda, estandarizado, mezclado, envasado y almacenado.

3. De acuerdo con los ensayos se determinó que el óptimo de sal fue de $3 \%$ y la proporción adecuada de pasta de tomate de árbol fue de $50 \%$ en relación con la pasta de rocoto.

\section{BIBLIOGRAFÍA}

Badui, S. Quimica de los Alimentos. Mexico Editores.

Espinoza, E, 1996.Evaluación Sensorial de Alimentos. UNJBG-Tacna-Perú.

Instituto de Nutrición, 1975. La composición de los alimentos peruanos. 3era Edición. Ministerio de Salud LimaPerú.

Mossel Y Quevedo (1987). Control Microbiológico de los Alimentos. Cleiba. Lima-Perú.

Paltrinieri, G. 1997. Procesamiento a pequeña escala de frutos y hortalizas nativos e introducidos. Editorial ProTempore del Tratado de Cooperación Amazónica. LimaPerú.

\section{ANEXOS}

ANEXO 01: Resultados de análisis Sensorial al Referido . A la cantidad de sal en la elaboración de salsa de rocoto.

\begin{tabular}{|c|c|c|c|c|c|}
\hline \multirow{2}{*}{ Panelistas } & \multicolumn{5}{|c|}{ Proporción de Sal \% } \\
\cline { 2 - 6 } & $\begin{array}{c}\mathbf{1} \\
(\mathbf{A})\end{array}$ & $\begin{array}{c}\mathbf{2} \\
\mathbf{( B )}\end{array}$ & $\begin{array}{c}\mathbf{3} \\
(\mathbf{C})\end{array}$ & $\begin{array}{c}\mathbf{4} \\
(\mathbf{D})\end{array}$ & $\begin{array}{c}5 \\
(\mathbf{E})\end{array}$ \\
\hline 1 & 4 & 3 & 4 & 3 & 4 \\
\hline 2 & 4 & 4 & 4 & 3 & 2 \\
\hline 3 & 3 & 4 & 4 & 4 & 3 \\
\hline 4 & 3 & 4 & 5 & 3 & 2 \\
\hline 5 & 3 & 4 & 4 & 3 & 3 \\
\hline 6 & 4 & 2 & 3 & 3 & 3 \\
\hline 7 & 3 & 3 & 5 & 2 & 4 \\
\hline 8 & 3 & 3 & 5 & 2 & 3 \\
\hline 9 & 3 & 3 & 4 & 3 & 2 \\
\hline 10 & 4 & 3 & 5 & 3 & 2 \\
\hline $\bar{X}$ & 3,4 & 3,3 & 4,3 & 2,9 & 2,8 \\
\hline$\in \mathbf{X}$ & 34 & 33 & 43 & 29 & 28 \\
\hline
\end{tabular}

ANEXO N 02: Resultado de Análisis Sensorial referido a la proporción de pasta de Tomate de árbol: pasta de rocoto.

\begin{tabular}{|c|c|c|c|c|}
\hline \multirow{2}{*}{ Panelistas } & \multicolumn{4}{|c|}{$\begin{array}{l}\text { Proporción de Pasta de } \\
\text { tomate de árbol }\end{array}$} \\
\hline & $\begin{array}{c}1 \\
\text { (A) }\end{array}$ & $\begin{array}{c}2 \\
\text { (B) }\end{array}$ & $\begin{array}{l}3 \\
\text { (C) }\end{array}$ & $\begin{array}{c}4 \\
\text { (D) }\end{array}$ \\
\hline 1 & 3 & 2 & 4 & 2 \\
\hline 2 & 2 & 2 & 4 & 2 \\
\hline 3 & 2 & 2 & 4 & 2 \\
\hline 4 & 2 & 3 & 3 & 2 \\
\hline 5 & 2 & 2 & 4 & 2 \\
\hline 6 & 2 & 2 & 4 & 2 \\
\hline 7 & 4 & 3 & 2 & 2 \\
\hline 8 & 2 & 2 & 3 & 2 \\
\hline 9 & 2 & 2 & 3 & 2 \\
\hline 10 & 2 & 2 & 4 & 2 \\
\hline $\bar{x}$ & 2,3 & 2,2 & 3,5 & 2,0 \\
\hline$\in \mathbf{x}$ & 23 & 22 & 35 & 20 \\
\hline
\end{tabular}

